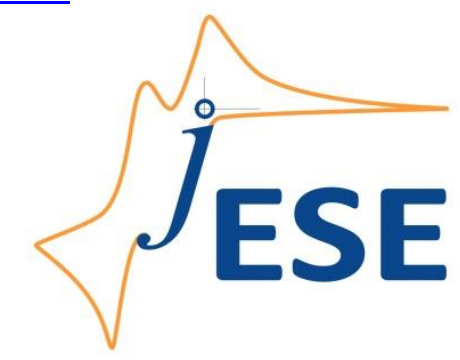

Open Access : : ISSN 1847-9286

www.jESE-online.org

Original scientific paper

\title{
Single microfluidic fuel cell with three fuels - formic acid, glucose and microbes: A comparative performance investigation
}

Jayapiriya Umarani Sivakumar ${ }^{1,3, *}$, Lanka Tata Rao ${ }^{2,3, *}$, Prakash Rewatkar ${ }^{1,3, *}$, Haroon Khan $^{4}$, Satish Kumar Dubey ${ }^{2,3}$, Arshad Javed ${ }^{2,3}$, Gyu Man Kim ${ }^{4}$ and Sanket Goel ${ }^{1,3, \square}$

${ }^{1}$ Department of Electrical and Electronics Engineering, BITS Pilani, Hyderabad Campus, Hyderabad, 500078, India

${ }^{2}$ Department of Mechanical Engineering, BITS Pilani, Hyderabad Campus, Hyderabad, 500078, India ${ }^{3}$ MEMS, Microfluidics and Nanoelectronics (MMNE) Lab, BITS Pilani, Hyderabad Campus, Hyderabad, 500078, India

${ }^{4}$ School of Mechanical Engineering, Kyungpook National University, Daegu, 41566, South Korea

*Equal contributions

Corresponding author: ${ }^{\bowtie}$ sgoel@hyderabad.bits-pilani.ac.in; Tel.: + 91-40-66303686

Received: August 19, 2021; Accepted: September 30, 2021; Published: October 5, 2021

\begin{abstract}
The development of microfluidic and nanofluidic devices is gaining remarkable attention due to the emphasis put on miniaturization of conventional energy conversion and storage processes. A microfluidic fuel cell can integrate flow of electrolytes, electrode-electrolyte interactions, and power generation in a microchannel. Such microfluidic fuel cells can be categorized on the basis of electrolytes and catalysts used for power generation. In this work, for the first time, a single microfluidic fuel cell was harnessed by using different fuels like glucose, microbes and formic acid. Herein, multi-walled carbon nanotubes (MWCNT) acted as electrode material, and performance investigations were carried out separately on the same microfluidic device for three different types of fuel cells (formic acid, microbial and enzymatic). The fabricated miniaturized microfluidic device was successfully used to harvest energy in microwatts from formic acid, microbes and glucose, without any metallic catalyst. The developed microfluidic fuel cells can maintain stable open-circuit voltage, which can be used for energizing various low-power portable devices or applications.
\end{abstract}

Keywords

electrocatalysis; biocatalysis; chemical fuel; biofuel; portable devices.

\section{Introduction}

The widespread interest in developing portable and miniaturized devices has led to the requirement of renewable and sustainable power sources for their operation, especially for critical 
biomedical and biochemical applications [1]. A miniaturized fuel cell is one of the best alternatives, capable of generating stable electrical energy and electricity from various fuels [2]. Depending on the application and power requirement, the catalysts in such fuel cells would be enzymes or microbes in powering biomedical implants or redox reagents for energizing micropower devices. In standard redox electrochemical fuel cells called chemical fuel cells (CFC), oxidation and reduction reactions occur on anode and cathode sides in the presence of fuel and oxidant, respectively [3]. Fuel cells that use enzymes and microbes as biocatalysts for the production of energy are termed enzymatic biofuel cells (EBFC) and microbial fuel cells (MFC), respectively [4,5]. As both EBFC and MFC utilize biosamples as electrolytes, they can be jointly termed as biofuel cells (BFC), where extensively biocompatible materials are used as a substrate for energy harvesting.

In EBFCs, the enzyme immobilized bio-electrodes catalyze fuel oxidation at the anode and the reduction of oxidant occurs at the cathode to produce power [6]. The power generation from EBFC can be utilized to power biomedical devices, like implantable devices or artificial organs, where fuel for the biofuel cell can be derived from physiological fluids [7]. Similarly, MFCs are bio-electrochemical devices that harness energy from bacterial metabolism to clean energy. The generation of power has been accomplished by the electrons derived from natural biochemical redox reactions catalyzed by bacteria oxidant at anode and cathode side, respectively [8,9]. As a result, it was successfully developed as a miniaturized biosensor and power source by utilizing various fluid resources such as domestic and industrial wastewater, urine, and soiled water from sewage $[10,11]$. In CFCs, chemical conversion of energy happens in the presence of electrolytes [12]. The CFCs are redox flow fuel cells, where electrolytes are fed continuously. A wide variety of fuel selection, high energy density and faster reaction kinetics have made CFC a significant energy harvesting device [13].

The operational efficiency and utilization of these fuel cells could be further improvised by the realization of a microfluidic platform. Microfluidic fuel cells ( $\mu \mathrm{FC})$ have great potential in portable applications $[14,15]$, which has led to the micro-fabrication of energy conversion devices. The fluid flow in microscale devices is governed by low Reynolds number, where viscous effects dominate over inertial forces. Contrary to the conventional fuel cell, these $\mu \mathrm{FC}$ operate based on the concept of co-laminar flow of liquids at the microscale, eliminating the requirement of an additional cation exchange membrane or separator [16]. This membrane-free architecture separates the anolyte and catholyte through a virtual liquid-liquid interface using a laminar fluid flow process [17]. As a result, the total form-factor and size of the device are reduced, and other related major problems, such as corrosion, humidification, and fuel crossover, are abridged or eliminated [18]. To maintain the colaminar fluid flow, the fuels and electrolytes are fed by external sources such as syringe pumps or peristaltic pumps. The inexpensive fabrication method and utilization of low-cost materials make $\mu \mathrm{FC}$ to be potential fuel cell technology for various applications [19].

Several techniques were used to fabricate portable miniaturized microfluidic devices, such as photolithography, soft-lithography [20], paper-based [21,22], xurography [23] and laser micromachining $[24,25]$. Despite their uniqueness and benefits, the development and implementtation of microfluidic fuel cells have not been utilized for portable electronic applications until now. The time-consuming procedures such as design and optimization of device parameters, fabrication protocols, selection [26] and incorporation of advanced electrode materials $[27,28]$ have hindered the microfluidic systems from being more applicable for real-time applications. This can be overcome by developing a single multifunctional microfluidic device capable of operating with a wide range of fuels. This will eventually lead to mass production of microdevices, making the processing time effective and commercially feasible. These aspects were the key challenges influencing the overall output performance. So far, 
several types of $\mu \mathrm{FC}$ have been successfully developed and reported [29-32] with description of device architecture for each type of fuel cell.

In this work, a single microfluidic platform incorporated with multi-walled carbon nanotube (MWCNT) electrodes was demonstrated to function with three different types of fuel cells (chemical, microbial, and enzymatic). The electrodes were fabricated using drop-casting method, and carbon nanomaterial as the electrode material. The microchannel was developed using a soft-lithography technique with the required microchannel height and width. Three different microfluidic fuel cells have been studied using different electrolytes, such as formic acid, microbes and glucose, on the same device with similar device parameters. In addition, various electrochemical characterizations were carried out to understand and analyze the electrocatalysis occurring during the energy harvesting process in terms of current density, power density and open circuit potential.

\section{Experimental}

\section{Chemicals and materials}

Glucose oxidase (GOx) (100,000 units/g solid) from Aspergillus niger, Laccase (E.C. 1.10.3.2, $24 \mathrm{U} / \mathrm{mg}$ ) from Trametes Versicolor and multi-walled carbon nanotubes (>8\% carboxylic acid functionalized) were procured from Sigma-Aldrich, India and used without any further modification. Analytical grade reagents, such as polyethylenimine (PEI), was procured from Sigma-Aldrich, India, and glutaraldehyde $40 \%$, formic acid $98 \%\left(\mathrm{CH}_{2} \mathrm{O}_{2}\right)$, sulphuric acid, $98 \%\left(\mathrm{H}_{2} \mathrm{SO}_{4}\right)$ were procured from $\mathrm{TCl}$ Chemicals Pvt. Ltd., India. Shewanella putrefaciens bacteria was procured from Microbial Type Culture Collection and Gene Bank, India and made into glycerol stocks for preservation. The media LuriaBertani (LB) broth, functionalized multi-walled carbon nanotube (MWCNT) and potassium ferricyanide were purchased from SRL, India. Polydimethylsiloxane (PDMS) was obtained from Dow Corning as Sylgard 184. Double-distilled $(18.2 \mathrm{M} \Omega \mathrm{cm}$ ) Milli-Q water was utilized to prepare all electrolytes. All electrochemical tests were conducted at room temperature conditions.

\section{Design, preparation, and fabrication of electrodes}

The standard photolithography technique has been used to fabricate the electrodes on an indium tin oxide (ITO) coated glass. The complete fabrication method has been adopted from the previously published research work [33]. The stepwise 3D schematic illustration of the electrode fabrication is displayed in Figure 1. In brief, the required electrode design with dimensions (length $20 \mathrm{~mm}$ and width $1 \mathrm{~mm}$ ) was created using photolithography techniques through a positive photoresist (AZ1512). Thereafter, the standard $98 \% \mathrm{HCl}$ chemical etchant was utilized to etch the desired pattern. This method will help to establish the desired pattern of electrodes with a conduction gap of $1 \mathrm{~mm}$ between them (Figure 1b). To enhance the surface-to-volume ratio and the morphological properties of the etched electrodes, MWCNT suspension $(1 \mathrm{mg} / \mathrm{ml}$ in DI water) was coated with the help of a PDMS stencil (Figure 1c). The detailed PDMS stencil fabrication process using spin coating was adopted from the previously published research article [34]. Using this stencil, three layers of MWCNT suspension were coated to achieve better step coverage and uniformity (Figure 1d). After every coating, the ITO substrate was dehydrated over the hot plate at $120^{\circ} \mathrm{C}$ for 1 hour, facilitating the MWCNT working area of $0.2 \mathrm{~cm}^{2}$ (Figure 1e). For MFC and CFC, the catalyst was used in the electrolytes which were flushed into the microfluidic device. In the case of EBFC, enzymes were immobilized on the MWCNT electrodes with the help of cross-linkers following the previously published work by our group [35]. 
Table 1. Detail parameters used for microfluidic fuel cells experimentations

\begin{tabular}{ccccc}
\hline No. & Components & $\begin{array}{c}\text { Microfluidic } \\
\text { chemical fuel cell }\end{array}$ & $\begin{array}{c}\text { Microfluidic } \\
\text { microbial fuel cell }\end{array}$ & $\begin{array}{c}\text { Microfluidic } \\
\text { enzymatic fuel cell }\end{array}$ \\
\cline { 2 - 5 } & Electrodes & \multicolumn{4}{c}{ Specifications } \\
\hline 1 & Microchannel & MWCNT \\
\hline 3 & Flow rate, $\mathrm{ml} / \mathrm{h}$ & PDMS & $3,6,12,18,24$ \\
\hline 4 & Anolyte & $\begin{array}{c}\text { Formic acid } \\
(0.2-3.5 \mathrm{M})\end{array}$ & $\begin{array}{c}\text { Shewanella putrefaciens } \\
(90 \mu \text { lin } 10 \text { ml LB broth) }\end{array}$ & $\begin{array}{c}\text { Glucose }(10-70 \mathrm{mM}) \\
\text { in PBS (0.1 M, pH 7) }\end{array}$ \\
\hline 5 & Catholyte & $\begin{array}{c}\text { Sulphuric acid } \\
(0.2-3.5 \mathrm{M})\end{array}$ & $\begin{array}{c}\text { Potassium ferricyanide } \\
(50 \mathrm{mM})\end{array}$ & PBS (0.1 M, pH 5) \\
\hline
\end{tabular}

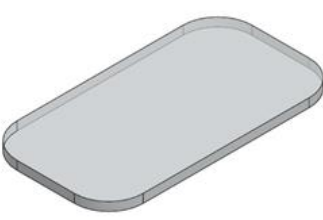

(a)

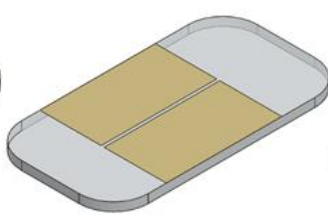

(b)

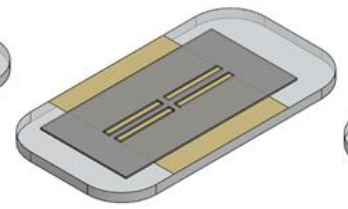

(c)

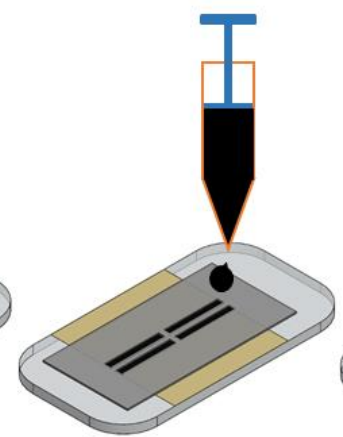

(d)

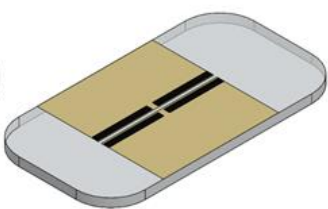

(e)

Figure 1. Stepwise 3D schematic illustration of etched ITO patterned with MWCNT electrode (a) ITO coated glass; (b) etched ITO glass with a gap of $1 \mathrm{~mm}$; (c) PDMS stencil aligned with electrodes; (d) MWCNT pipetting for electrodes; (e) MWCNT electrodes

\section{Fabrication and integration of microchannel}

The soft-lithography technique was used to fabricate the Y-shaped microchannel using PDMS polymer. Prior to microchannel fabrication, a hydrogel mold was created by utilizing the previously reported protocol [36]. Subsequently, the PDMS microchannel fabrication has been done by using hydrogel mold with the conventional scientific protocol [15]. The detailed Y-shaped PDMS microchannel fabrication protocol process was adopted from the previously published research work [29]. The required inlets and outlets were created using a needle (blunt type) to stream the electrolytes. Finally, the whole microfluidic fuel cell was realized by integrating the microchannel with MWCNT electrodes sealed in an acrylic case with screws to prevent leakage. Detailed stepwise microfluidic fuel cell integration process is depicted in Figure 2.

\section{Electrochemical method}

To understand the electrochemical behavior of the fabricated MWCNT electrodes, various characterizations were carried out using an electrochemical workstation (Biologic Instruments). A three-electrode system consisting of MWCNT, platinum wire and $\mathrm{Ag} / \mathrm{AgCl}(3 \mathrm{M} \mathrm{KCl})$ as working, counter and reference electrode, respectively. Initially, cyclic voltammetry (CV) was conducted to find the redox behavior of the fabricated bioelectrode in the voltage range suitable for the working electrode and electrolytes. Likewise, other electrochemical techniques, such as chronoamperemetry (CA) and linear sweep voltammetry (LSV), were performed to record the performance of the microfluidic fuel cell at different electrolytic conditions (chemical, microbial, and enzymatic). 


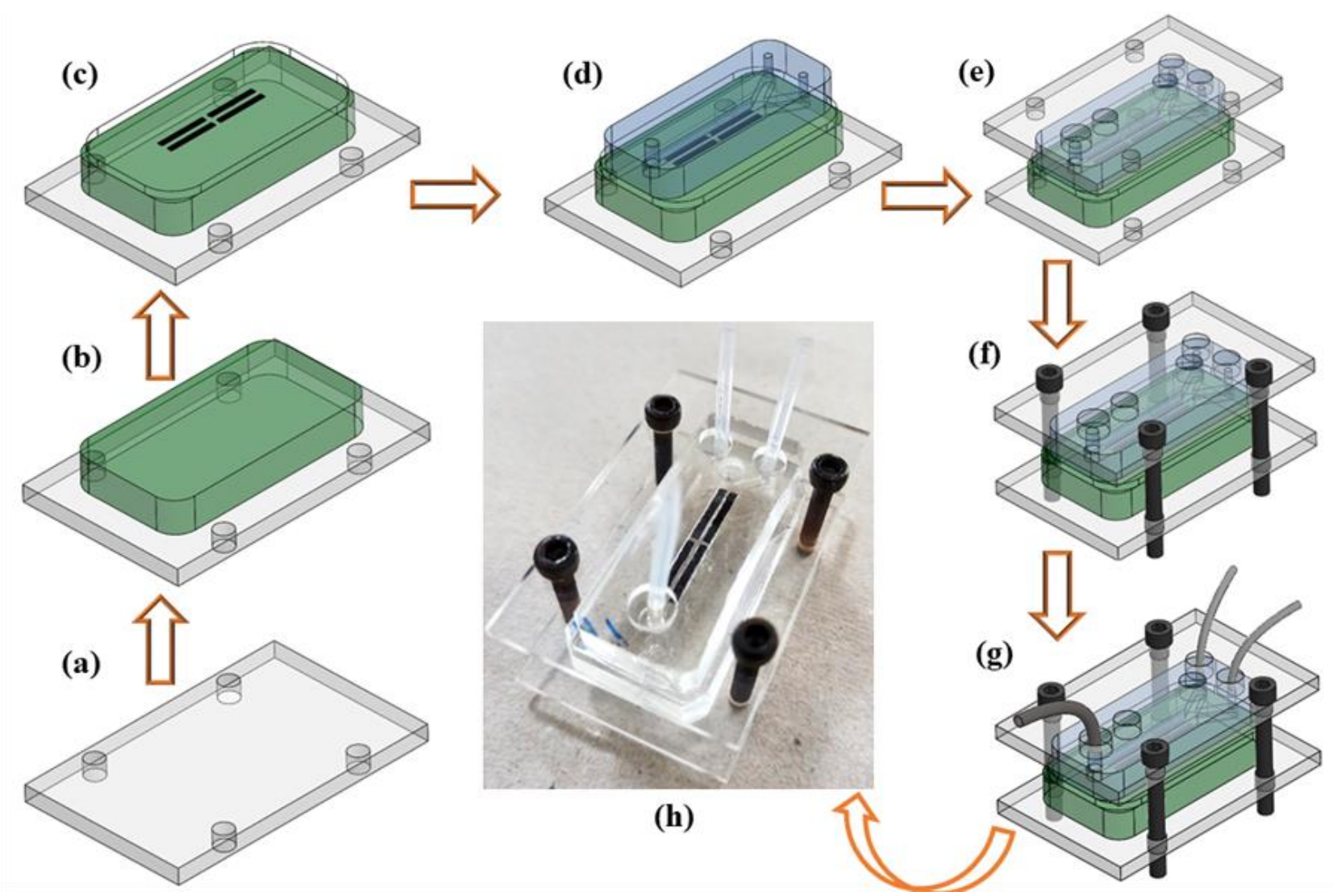

Figure 2. Step-by-step fabrication of membraneless microfluidic fuel cell: (a) bottom support (acrylic); (b) PDMS support for electrodes; (c) MWCNT electrodes; (d) microchannel with electrodes; (e) top support; (f) bolt and nut mechanism for preventing leakage; $(\mathrm{g})$ complete fuel cell with inlets and outlet; $(\mathrm{h})$ real time integrated device

\section{Results and discussion}

\section{Microfluidic chemical fuel cell (MCFC)}

Here, formic acid and atmospheric oxygen were used as fuel and oxidant, respectively. Further, sulphuric acid was used as an electrolyte for ionic conductivity. The fuel and electrolyte were fed into the cell by a peristaltic pump with a flow rate $(6 \mathrm{ml} / \mathrm{hr})$ to form co-laminar flow. This co-laminar flow acts as a virtual membrane for the fuel cell at the liquid-liquid interface.

\section{Electrolyte optimization}

Prior to the performance study of the cell, electrochemical investigations were carried out using the electrochemical workstation. The electrochemical behaviour of anode and cathode (MWCNT electrodes) was studied with various fuel and electrolyte concentrations.

The fuel and electrolyte concentrations were optimized by the linear sweep voltammetry (LSV) technique at standard scan rate of $50 \mathrm{mV} / \mathrm{s}$. The detailed experimentation parameters are listed in Table 1. The fuel and electrolyte optimization is given in Figure 3. As shown in Figure 3a, the fuel and electrolyte concentrations were varied in a uniform increment (0.2 M-3.5 M). Correspondingly, electrochemical activity was observed in terms of current density (CD). As shown in Figure 3a, the maximum $C D$ was observed at $1 \mathrm{M}$ of formic acid and $1.5 \mathrm{M}$ of sulphuric acid. With a further increase in concentration, there was no increment observed in $C D$. This manifests that the electrons transfer kinetics has been in line with the electrochemical reaction. Subsequently, the cyclic voltammetry (CV) technique was used to identify the behaviour of MWCNT electrodes with optimized fuel and electrolyte concentration solutions [37]. 

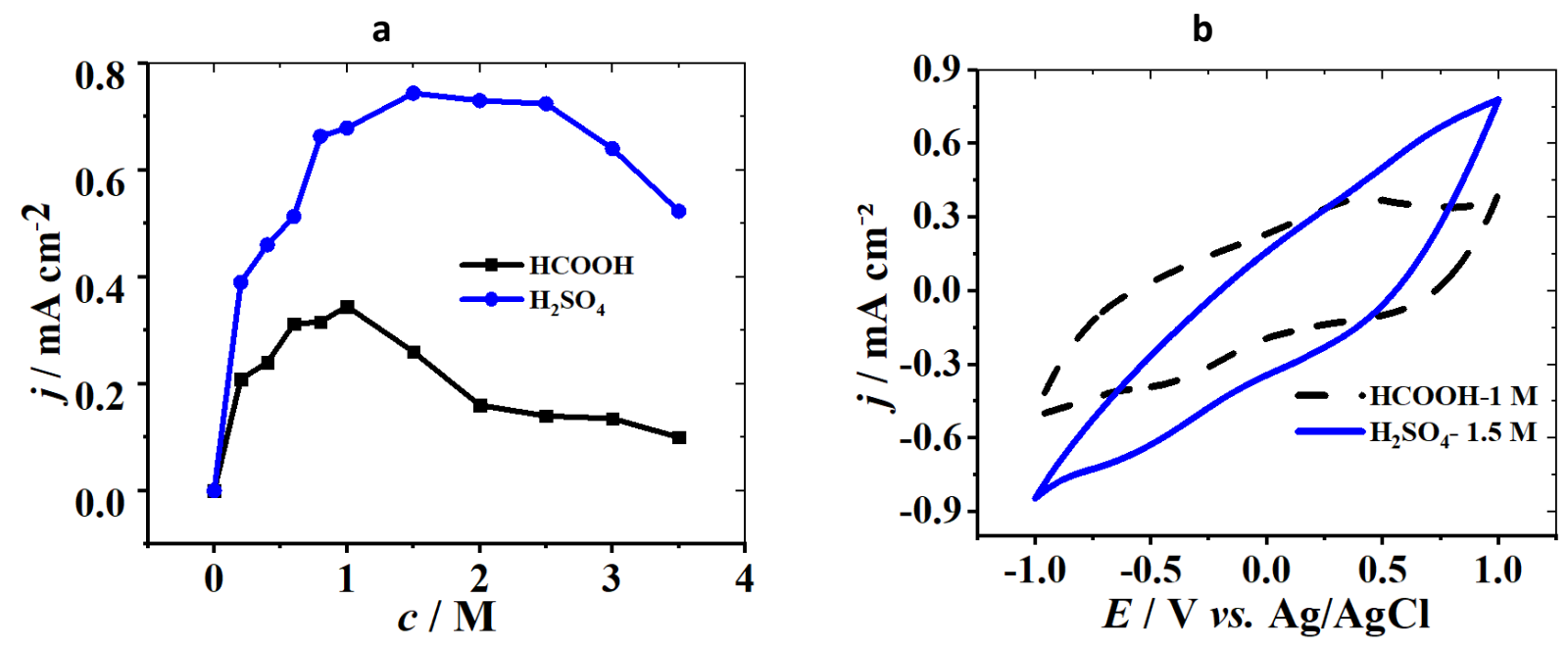

Figure 3. The individual fuel and electrolyte solution optimization at various concentrations (M), (a) optimization; (b) CV responses at optimized concentrations

The optimized fuel and electrolyte CV responses are depicted in Figure $3 \mathrm{~b}$. The maximum CD hysteresis was observed at optimized fuel and electrolyte concentrations. As shown in Figure 3b, no oxidation and reduction peaks were observed at electrodes with optimized fuel and electrolyte, meaning that no catalyst was present on MWCNT electrodes. From the literature [38], catalyst electrodes have shown more redox peaks compare to plain electrodes. Therefore, the fabricated MCFC with plain MWCNT electrodes has drawn lower performance, but these electrodes are inexpensive.

\section{Polarization performance}

After successful optimization of the electrode parameters, MCFC performance was investigated by chronoamperometry (CA) technique. Here, $1 \mathrm{M}$ of formic acid and $1.5 \mathrm{M}$ of sulphuric acid were used as fuel and electrolyte, respectively. Plain MWCNT were used as electrodes and atmospheric oxygen as the oxidant. The real-time experimentation setup of MCFC is depicted in Figure $2 \mathrm{~h}$. To observe the MCFC performance, anode and cathode were connected to the electrochemical workstation with external sources. Initially, a stable open circuit potential (OCP) of $510 \mathrm{mV}$ was observed. Subsequently, the performance of the fuel cell was investigated with stable OCP for a range of flow rates (3-24 $\left.\mathrm{ml} \mathrm{h}^{-1}\right)$. It was found that at particular optimized flow rate $\left(6 \mathrm{ml} \mathrm{h}^{-1}\right)$, the co-laminar flow of MCFC is very stable, and the diffusion zone has been dominated over depletion zones. Due to these reasons, MCFC provided the highest performance at $6 \mathrm{ml} / \mathrm{h}$ flow rate. The output polarization of MCFC was measured in terms of current density (CD) and power density (PD). The MCFC output is depicted in Figure 4 in terms of voltage, CD, and power density (PD). As can be seen from Figure 5, the optimized MCFC shows the maximum PD of $3.195 \mu \mathrm{W} \mathrm{cm}{ }^{-2}$ at the maximum $\mathrm{CD}$ of $16.85 \mu \mathrm{A} \mathrm{cm}{ }^{-2}$ at $6 \mathrm{ml} \mathrm{h}^{-1}$ of flow rate.

Microfluidic microbial fuel cell (MMFC)

Bacterial optical and inoculation study

In the microbial fuel cell, the bacteria Shewanella putrefaciens was used as a biocatalyst. $90 \mu \mathrm{l}$ of this bacteria was inoculated in $10 \mathrm{ml}$ of autoclaved in Luria-Bertani (LB) media and incubated for 8 hours at $37^{\circ} \mathrm{C}$. The inoculation study was accomplished at three time periods, such as 6,8 , and 14 hours at a fixed $37^{\circ} \mathrm{C}$ followed by optical density measurement. Amongst all, the 8-hour incubation time was ideally selected with an optical density (OD at $620 \mathrm{~nm}$ ) of 0.73 . These optimized 
parameters were referred from the recently published research article [32]. The ideal 8-hour incubation time exhibited higher metabolic activity and significant replication rates compared to others. The detailed bacterial optical and incubation study are graphically plotted and elaborated in previous studies done by our group [32].

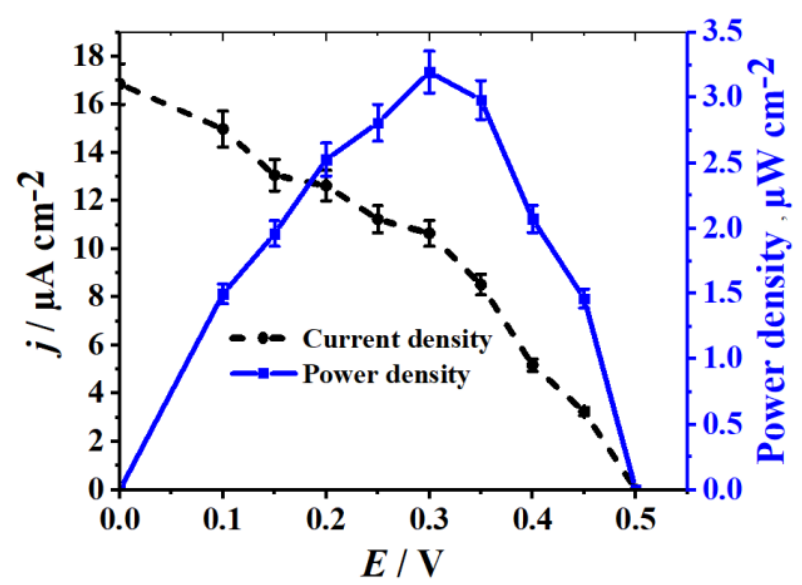

Figure 4. Polarization and power performance of MCFC at optimized fuel and electrolyte solutions with MWCNT electrodes (1 $\mathrm{M}$ of formic acid and $1.5 \mathrm{M}$ of sulphuric acid), with standard deviation $(n=3)$

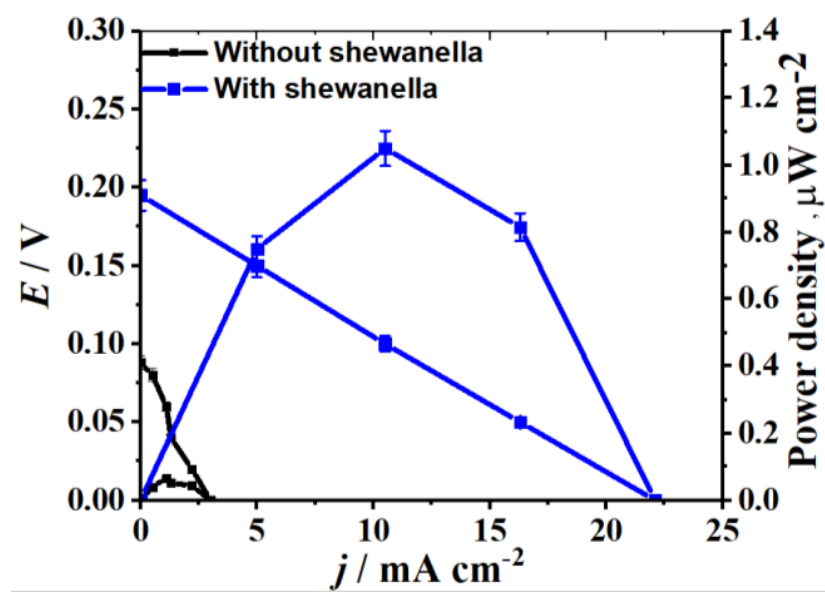

Figure 5. Polarization and power performance of microfluidic microbial fuel cell with standard deviation $(n=3)$

\section{Polarization study}

After the successful biofuel preparation, the ITO-based MMFC was continuously tested by feeding Shewanella putrefaciens as anolyte and $50 \mathrm{mM}$ potassium ferricyanide in PBS $(0.1 \mathrm{M}, \mathrm{pH} 7)$ as catholyte at a flow rate of $6 \mathrm{ml} /$ hour. During experimentation, initially the open circuit potential (OCP) was measured. After that, the polarization study was evaluated at the stable OCP. This study was carried out in a two-electrode configuration using potentiostat where the electrochemical CA technique was used to calculate the power performance. Detailed comparative results of MMFC are summarized in Table 2. As shown in Figure 5, the developed MWCNT coated MMFC in the presence of inoculated S. putrefaciens delivered the maximum OCP of $0.195 \mathrm{~V}$, with maximum power density (MPD) of $1 \mu \mathrm{W} \mathrm{cm} \mathrm{cm}^{-2}$ and maximum current density (MCD) of $22.1 \mu \mathrm{A} \mathrm{cm}{ }^{-2}$. Likewise, the power performance of media (absence of $S$. putrefaciens) was observed in the same device to study the role of MWCNT material [39] and inoculated bacteria for an efficient electrochemical redox reaction. Although the obtained output power is not too high, it can be improved after amendment in the design, electrochemistry, and catalyst loading [40].

\section{Microfluidic enzymatic fuel cell (MEFC)}

\section{Bioelectrode characterization}

The optimum parameters for bioelectrodes and their biocatalytic activity were characterized using electrochemical techniques. The enzyme immobilization and crosslinking procedures were adopted from our previously published work to prepare bioelectrodes [20]. In brief, bioanode and biocathode were prepared by drop-casting $10 \mu$ of glucose oxidase $\left(4 \mathrm{mg} \mathrm{ml}^{-1}\right)$ and laccase $\left(4 \mathrm{mg} \mathrm{ml}^{-1}\right)$ respectively, on the MWCNT electrode surface. A three-electrode system was used to study the electrocatalytic behavior of bioelectrodes. An electrode surface of $0.2 \mathrm{~cm}^{2}$ was considered, and all the reactions were carried out in PBS (0.1 M). Initially, the glucose concentration was determined by the LSV technique. As summarized in Table 1, various glucose concentrations in the range of 10-70 mM were considered 
and $50 \mathrm{mM}$ was found to be the optimal concentration, as shown in Figure 6a. The current density after $50 \mathrm{mM}$ decreased and got saturated. With $50 \mathrm{mM}$ fuel concentration, the bioanode was characterized in the presence and absence of glucose, which provided information about the oxidative behavior of the electrodes [41]. In the presence of glucose, a visible peak occurred at $0.3 \mathrm{~V}$ with a maximum current density of $0.6 \mathrm{~mA} \mathrm{~cm}^{-2}$. This corresponds to the oxidation of glucose [42] into gluconolactone (Figure $6 \mathrm{~b}$ ), denoting the occurrence of efficient biocatalysis. Similarly, biocathode was also studied using the CV technique.

a

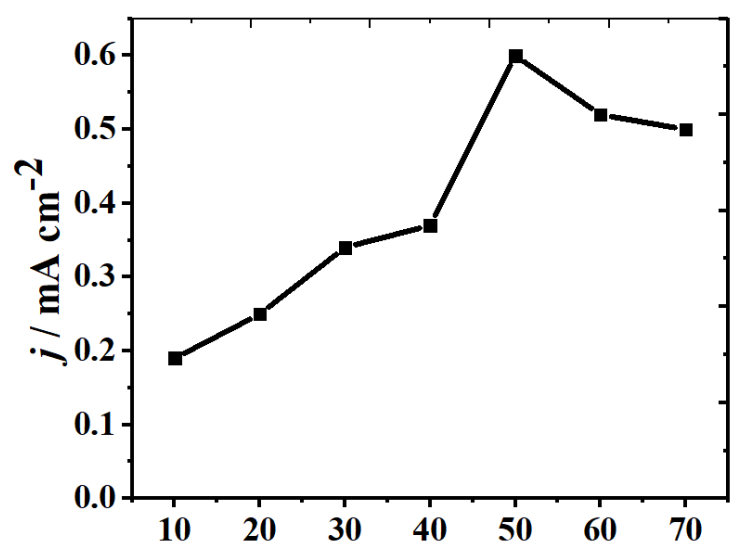

Glucose concentration, $\mathrm{mM}$

C

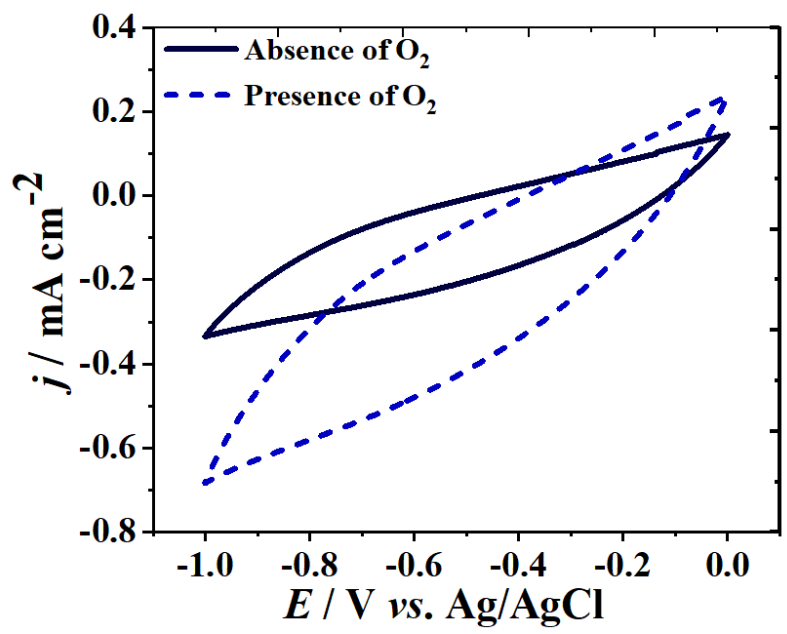

b

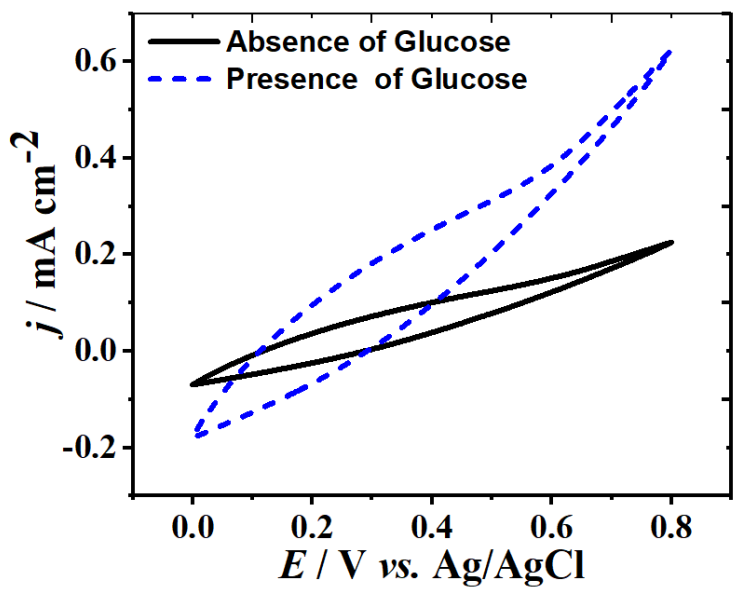

d

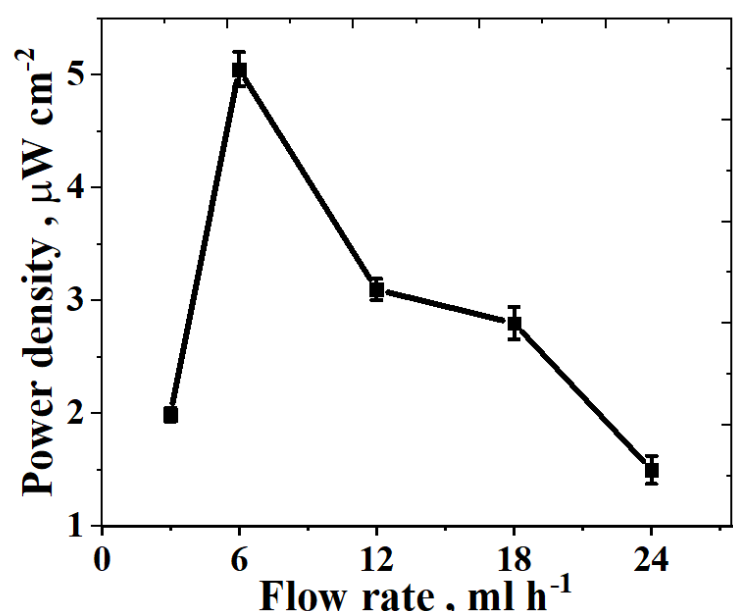

Figure 6. (a) Optimization of glucose concentration; (b) bioanode characterization; (c) biocathode characterization; (d) optimization of flow rate

The biocathodes were tested in the presence and absence of oxygen conditions. In the presence of oxygen, the maximum catalytic current density of $0.7 \mathrm{~mA} \mathrm{~cm}{ }^{-2}$ was observed in Figure $6 \mathrm{c}$ due to the cupric ions redox reaction happening during the enzymatic mechanism of laccase at a voltage of $-0.6 \mathrm{~V}$ [43]. This confirms the efficient immobilization of enzyme and oxygen prominence during the cathodic reaction process [35].

\section{Device optimization and analysis}

The optimized fuel concentration was incorporated into the microfluidic device to study the polarization performance of the MEFC. Subsequently, the flow rate, at which the electrolyte should be flushed into the MEFC was optimized. As it can be seen from Figure $6 \mathrm{~d}$, a flow rate of $6 \mathrm{ml} \mathrm{h}^{-1}$ produced higher power density as better co-laminar flow was maintained in comparison to other 
flow rates because of which the power output was high [44]. This is due to the fact that at higher flow rates enzymes detachment could occur leading to lower biocatalysis [45]. Following the optimization of flow rate and fuel concentration, the performance of the MEFC was studied using chronoamperometric technique. The MEFC delivered a maximum open-circuit voltage (OCV) of $325 \mathrm{mV}$. As shown in Figure 7, the microfluidic fuel cell produced a maximum power output of $5.5 \mu \mathrm{W} \mathrm{cm}{ }^{-2}$ with the highest current density of $68 \mu \mathrm{A} \mathrm{cm}{ }^{-2}$. This power output is suitable for a MEFC without using any mediator.

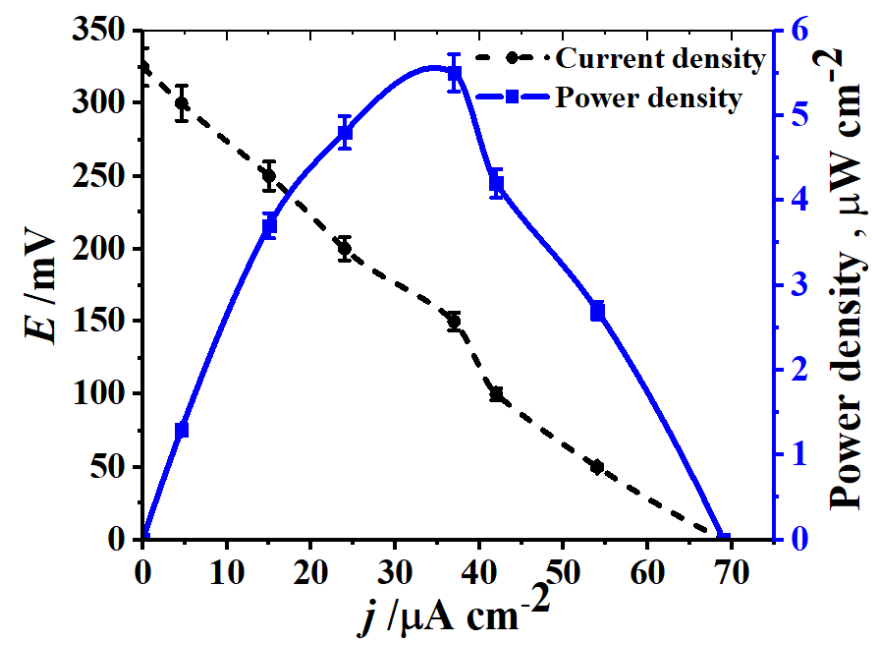

Figure 7. Polarization and power density curves for optimized bioelectrodes and device parameters with standard deviation $(n=3)$

Table 2. Summary of optimized fuel cell parameters and performance

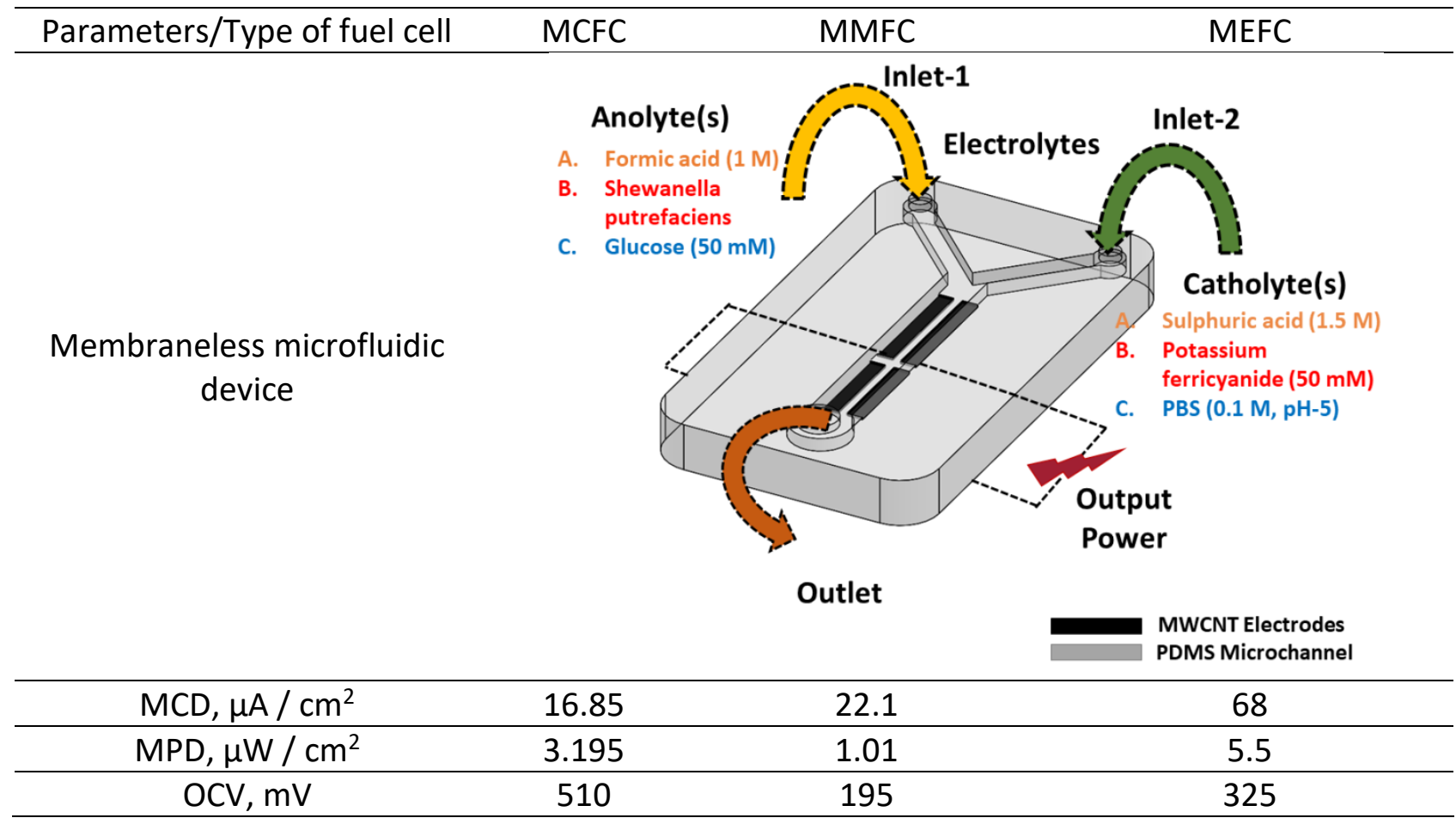

\section{Conclusions}

This work demonstrates the successful development and implementation of a single microfluidic platform for three different types of fuel cells. The novelty of this work lies in the ability to utilize a single miniaturized platform with optimized cell dimensions for three types of major fuel cells. 
Microfluidic device was fabricated using a soft-lithography process and the MWCNT electrodes were prepared by the simple drop-casting method. Such fabricated microfluidic devices and electrodes are very inexpensive (less than \$1), yet a single device can function as different fuel cells. With optimized device parameters, the microfluidic device was capable of operating at electrolyte conditions of three variant fuels and oxidants with stable open-circuit voltage. The complete summary of the operating parameters in the different micro fuel cells is given in Table 2. Higher power output could be achieved by utilizing advanced composite nanomaterials and stacking of electrodes. This work opens the new scope of development for trilateral fuel cells exclusively on a single platform in the future using adaptive operating parameters.

Acknowledgement: The authors are thankful to the Department for Scientific \& Industrial Research (DSIR) for financial assistance under the funded project DSIR/PRISM/60/2018.

\section{References}

[1] M. Safdar, J. Jänis, S. Sánchez, Lab on a Chip 16(15) (2016) 2754-2758. https://doi.org/10.1039/C6LC90070D

[2] S.O. Ganiyu, C.A. Martínez-Huitle, Current Opinion in Electrochemistry 22 (2020) 211-220. https://doi.org/10.1016/i.coelec.2020.07.007

[3] E. Kjeang, N. Djilali, D. Sinton, Journal of Power Sources 186(2) (2009) 353-369. https://doi.org/10.1016/i.jpowsour.2008.10.011

[4] S. Goel, Applied Materials Today 11 (2018) 270-279. https://doi.org/10.1016/i.apmt.2018.$\underline{03.005}$

[5] P. Rewatkar, S. Goel, Journal of Electrochemical Science and Engineering 10(1) (2020) 4954. https://doi.org/10.5599/jese.687

[6] M. Rasmussen, S. Abdellaoui, S.D. Minteer, Biosensors and Bioelectronics 76 (2016) 91-102. https://doi.org/10.1016/i.bios.2015.06.029

[7] G. Slaughter, T. Kulkarni, Journal of Biochips and Tissue Chips 5(1) (2015) 1000111. https://doi.org/10.4172/2153-0777.1000110

[8] R. Veerubhotla, A. Bandopadhyay, D. Das, S. Chakraborty, Lab on a Chip 15(12) (2015) $2580-$ 2583. https://doi.org/10.1039/C5LC00211G

[9] M. Bandapati, S. Goel, B. Krishnamurthy, Journal of Electrochemical Science and Engineering 10(4) (2020) 385-398. https://doi.org/10.5599/jese.807

[10] Y. Yang, D. Ye, J. Li, X. Zhu, Q. Liao, B. Zhang, Journal of Power Sources 324 (2016) 113-125. https://doi.org/10.1016/i.jpowsour.2016.05.078

[11] A.N. Ghadge, M. Sreemannarayana, N. Duteanu, M.M. Ghangrekar, Journal of Electrochemical Science and Engineering 4(4) (2014) 315-326. https://doi.org/10.5599/jese.2014.0047

[12] K. Ponmani, S. Kiruthika, B. Muthukumaran, Journal of Electrochemical Science and Technology 6(3) (2015) 95-105. https://doi.org/10.5229/JECST.2015.6.3.95

[13] Y. Zhou, X. Zhu, B. Zhang, D.-D. Ye, R. Chen, Q. Liao, International Journal of Hydrogen Energy 45(53) (2020) 29235-29245. https://doi.org/10.1016/i.ijhydene.2020.07.169

[14] M. Bhaiyya, P. Rewatkar, M. Salve, P.K. Pattnaik, S. Goel, IEEE Transactions of NanoBioscience 20(1) (2020) 79-85. https://doi.org/10.1109/tnb.2020.3036642

[15] S. Dudala, S.K. Dubey, S. Goel, IEEE Transactions of Biomedical Circuits and Systems 13(6) (2019) 1518-1524. https://doi.org/10.1109/TBCAS.2019.2939658

[16] S.A. Mousavi Shaegh, N.-T. Nguyen, S.H. Chan, International Journal of Hydrogen Energy 36(9) (2011) 5675-5694. https://doi.org/10.1016/i.ijhydene.2011.01.063

[17] R. Banerjee, S.P.J. Kumar, N. Mehendale, S. Sevda, V.K. Garlapati, Renewable and Sustainable Energy Reviews 101 (2019) 548-558. https://doi.org/10.1016/i.rser.2018.11.040 
[18] E.R. Choban, L.J. Markoski, A. Wieckowski, P.J.A. Kenis, Journal of Power Sources 128(1) (2004) 54-60. https://doi.org/10.1016/i.jpowsour.2003.11.052

[19] J. wook Lee, E. Kjeang, Biomicrofluidics 4(4) (2010) 041301. https://doi.org/10.1063/1.3515523

[20] J. U.S., P. Rewatkar, S. Goel, International Journal of Hydrogen Energy 46(4) (2020) 31833192. https://doi.org/10.1016/j.ijhydene.2020.06.133

[21] L. Tata Rao, P. Rewatkar, S.K. Dubey, A. Javed, S. Goel, International Journal of Energy Research 44(5) (2020) 3893-3904. https://doi.org/10.1002/er.5188

[22] D. Nath, P. Sai Kiran, P. Rewatkar, B. Krishnamurthy, P. Sankar Ganesh, S. Goel, IEEE Transactions of NanoBioscience 18(3) (2019) 510-515. https://doi.org/10.1109/TNB.2019.$\underline{2919930}$

[23] L. Renaud, D. Selloum, S. Tingry, Microfluidics and Nanofluidics 18(5-6) (2015) 1407-1416. https://doi.org/10.1007/s10404-014-1539-z

[24] S. Srikanth, S. Dudala, S. Raut, S.K. Dubey, I. Ishii, A. Javed, S. Goel, Journal of Micromechanics and Microengineering 30(9) (2020) 095003. https://doi.org/10.1088/13616439/ab92ea

[25] S. Dudala, L.T. Rao, S.K. Dubey, A. Javed, S. Goel, Materials Today: Proceedings 28 (Part 2) (2019) 804-807. https://doi.org/10.1016/j.matpr.2019.12.302

[26] J. Wei, P. Liang, X. Huang, Bioresource Technology 102(20) (2011) 9335-9344. https://doi.org/10.1016/i.biortech.2011.07.019

[27] D. Pant, G. Van Bogaert, L. Diels, K. Vanbroekhoven, Bioresource Technology 101(6) (2010) 1533-1543. https://doi.org/10.1016/i.biortech.2009.10.017

[28] A.A. Babadi, S. Bagheri, S.B.A. Hamid, Biosensensors and Bioelectronics 79 (2016) 850-860. https://doi.org/10.1016/i.bios.2016.01.016

[29] P. Rewatkar, A. Kothuru, S. Goel, IEEE Transactions of Electron Devices 67(4) (2020) $1832-$ 1838. https://doi.org/10.1109/ted.2020.2971480

[30] L.T. Rao, S.K. Dubey, A. Javed, S. Goel, Journal of Electrochemical Energy Conversion and Storage 17(3) (2020) 031015. https://doi.org/10.1115/1.4045979

[31] P. Rewatkar, J. U. S, S. Goel, ACS Sustainable Chemistry \& Engineering 8(32) (2020) $12313-$ 12320. https://doi.org/10.1021/acssuschemeng.0c04752

[32] D. Nath, S. Kallepalli, L.T. Rao, S.K. Dubey, A. Javed, S. Goel, International Journal of Hydrogen Energy 46(4) (2020) 3230-3239. https://doi.org/10.1016/i.ijhydene.2020.04.294

[33] H. Khan, C.M. Kim, S.Y. Kim, S. Goel, P.K. Dwivedi, A. Sharma, Y.H. Kim, G.M. Kim, International Journal of Precison Engineering and Manufacturing-Green Technology 6(3) (2019) 511-520. https://doi.org/10.1007/s40684-019-00056-x

[34] W.E. Farneth, M.B. D'Amore, Journal of Electroanalytical Chemistry 581(2) (2005) 197-205. https://doi.org/10.1016/i.jelechem.2005.03.018

[35] U.S. Jayapiriya, S. Goel, Applied Nanoscience 10(11) (2020) 4315-4324. https://doi.org/10.1007/s13204-020-01543-3

[36] T.D. Dang, Y.H. Kim, J.H. Choi, G.-M. Kim, Journal of Micromechanics and Microengineering 22(1) (2012) 015017. https://doi.org/10.1088/0960-1317/22/1/015017

[37] L.T. Rao, S.K. Dubey, A. Javed, S. Goel, Sustainable Energy Technology and Assessments 45 (2021) 101176. https://doi.org/10.1016/J.SETA.2021.101176

[38] D. Panjiara, H. Pramanik, Journal of Electrochemical and Technology 12(1) (2021) 38-57. https://doi.org/10.33961/jecst.2020.01102

[39] Y. Wu, S. Wang, D. Liang, N. Li, Bioresource Technology 298 (2020) 122403. https://doi.org/10.1016/i.biortech.2019.122403

[40] S. Zhu, H. Li, W. Niu, G. Xu, Biosensensors and Bioelectronics 25(4) (2009) 940-943. https://doi.org/10.1016/i.bios.2009.08.022 
[41] J.U.S, S. Goel, Sustainable Energy Technology and Assessments 42 (2020) 100811. https://doi.org/10.1016/i.seta.2020.100811

[42] M. Bandapati, B. Krishnamurthy, S. Goel, IEEE Transactions of NanoBioscience 18(2) (2019) 170-175. https://doi.org/10.1109/tnb.2019.2896207

[43] P. Rewatkar, S. Goel, IEEE Transactions of NanoBioscience 17(4) (2018) 374-379. https://doi.org/10.1109/TNB.2018.2857406

[44] M.H. Sun, G. Velve Casquillas, S.S. Guo, J. Shi, H. Ji, Q. Ouyang, Y. Chen, Microelectronic Engineering 84(5-8) (2007) 1182-1185. https://doi.org/10.1016/j.mee.2007.01.175

[45] A. Zebda, L. Renaud, M. Cretin, C. Innocent, F. Pichot, R. Ferrigno, S. Tingry, Journal of Power Sources 193(2) (2009) 602-606. https://doi.org/10.1016/i.jpowsour.2009.04.066

(C)2021 by the authors; licensee IAPC, Zagreb, Croatia. This article is an open-access article distributed under the terms and conditions of the Creative Commons Attribution license (https://creativecommons.org/licenses/by/4.0/) 